\title{
Air Rail Links and Risk Analysis of Prague Airport Project
}

\author{
L. Bína* \& P. Moos \& O.Pastor \\ Czech Technical University in Prague, Faculty of Transportation Sciences \\ *Corresponding author: bina@fd.cvut.cz
}

\begin{abstract}
This paper describes the problems related to the integration of air and railway transport, which require building railway connections to hub airports, especially networks of long distance railways and high-speed tracks that link large cities with airport terminals. It presents and analyzes some solutions that have been implemented in Europe and focuses on a similar project which is currently being prepared in the Czech Republic at the dynamically growing international airport in Prague. For the final decision making process concerning the possibilities of a rail connection between Prague city and its airport a comprehensive comparative study, including risk analysis, was processed by the Czech Technical University in Prague, Faculty of Transportation Sciences.
\end{abstract}

KEY WORDS: airport, Prague airport, hub airport, airport and railway network, high-speed tracks, intermodal transportation.

\section{INTRODUCTION}

Present economic and social development in its global dimension creates more and more demands on transport. Transportation is provided by various transport means, each having benefits, as well as disadvantages. Good co-operation and utilization of the advantages of each transport mode in their particular link of the transport chain, where they can provide the most benefit, is the best hope for the future.

Air transport has the strongest position in respect of long distance transportation. Speed is its greatest advantage, although there are also some significant disadvantages. Longdistance air transport is assured though a relatively sparse network of hub airports, construction of which is very demanding from a financial point of view. Modern airports are also very demanding from the viewpoint of space, and, due to their unfavourable influence on the environment and health, are erected mostly on the outskirts of built-up areas. On the other hand, hubs are erected in the areas in which there is an important flow of passengers and goods to be transported by airplanes. This shows that modern airports are intermodal terminals, usually comprising of air, rail and road transport, and, in some cases, even water-borne transport. As the overwhelming majority of passengers start and end their journeys within developed areas, it is necessary to assure appropriate subsequent transport. In respect of servicing big airports, rail tracks particularly come into consideration for connecting the airport and adjacent cities, and, eventually, urban agglomerations, as well as for the transportation covering medium-length distances, when the collection and distribution of passengers is executed from and to neighbouring 
towns which either do not have their own airports, or where the realization of direct flights would be inefficient or unsuitable for other reasons. The big perspective envisages the harmonization of long-distance air transport and high-speed railway transport within continents.

\section{INTERMODAL CONCEPT OF A MODERN AIRPORT}

Modern hub airports integrate air transport mainly with long-distance rail transport and, in some cases, water-borne transport. Road network connections are being implemented in all airports. This inter-modal system is built-up in accordance with the principles stated below:

Future economic model of air transport functioning could include:

- Conventional network carriers offering their services in alliances,

- Regional companies (independent or as daughter companies of bigger firms),

- Rental carriers,

- Low-cost airlines.

\section{Where:}

- Network carriers will focus on long-distance and intercontinental flights,

- New companies established by these network carriers will constitute "feeders" for longdistance flights, thereby taking over some parts of the low-cost airlines' clientele,

- Regional carriers will supply demand for regional airport services,

- Low-cost airlines will specialize in direct flights,

- Low-cost airlines will compete with companies specialized in flights to order (rental carriers).

\section{The Integration of Air and Railway Transport}

To realize the above-mentioned integration of air and railway transport, railway stations are being built mainly at airports in attraction zones, thus enabling the intended cooperation between air transport and railway traffic. Two options are available: either to connect the high-speed railway line directly with the railway station at the respective airport or to interconnect airports with a suburban railroad, or eventually a specialized high-speed railway line (e.g. Heathrow Express in London, etc.).

\section{A possible recommendation could be that the inter-modal product meets the following requirements:}

- Guaranty of connections - This means that passengers with an integrated fare ticket have to be sure that they will not be left halfway due to delays,

- Inter-modal portal - This involves a unified source of information for passengers,

- Central marketing - The inter-modal product has to be offered by all participating carriers together,

- Related services at the baggage delivery office. This refers to information on connecting transportation, ticket sales, etc.

\section{As part of the abovementioned integration, several airports currently offer the following} services:

- Transport of individuals to the airport by special trains,

- Baggage carriage - DB offers to carry passengers' baggage, which has to be submitted three days prior to departure. In Switzerland, SBB offers baggage carriage from more 
than fifty railway stations one-day prior to departure, including customs clearance, while passengers receive their boarding cards at the same time,

- Check-in, checkout - The passenger has the possibility to check-in at other places than the airport (automated machines, phone, fax, web/wap). During the check-in, the passenger receives all necessary travel documents (boarding card, baggage label, baggage tag). The check-out takes place not at the final destination airport but at the final railway station,

- Ticketing - This involves offering a combined travel document: "train ticket - air ticket".

- Information - This refers to the possibility of getting access to important updated information about air transport at places other than only the airport (system Travelnet Fraport, Infoflyway - Lufthansa, Infoplattform - RMV).

\section{General requirements for inter-modality according to passengers' demands could be formulated as follows:}

- Short travel period - This includes an optimization of the actual time of transfer and time spent at the airport. For transcontinental flights, services with a higher level of comfort should be offered,

- Check-in and baggage carriage - If possible, only one check-in with the first carrier to be used by the passenger, and to whom he would submit the baggage. Baggage collection should take place from the last carrier once at the final destination,

- Clearance during the travel,

- Integrated travel document.

In order to implement an intermodal terminal and intermodal transportation product in hub airports it is necessary to assure the connection of airports with the railway network, and namely high-speed train networks, which, in their parameters, come close to air transport parameters. As regards the situation in Europe, there was a survey and overview of subsequent land transport at 65 of the most important European airports undertaken by Jan Perner Transport Faculty University of Pardubice in 2004 (status as of December 31, 2004).

\section{This overview shows:}

- 45 airports have rail and other connections

- 6 airports have underground lines (metro) or light suburban rail transport

- 14 airports have only road connections

On the grounds of the abovementioned survey we can also state that there are only four cities with more than 1 million inhabitants having an important airport which is not connected with the city by a rail transport. These are: Marseille, Prague, Warsaw and Budapest. On the other hand, there are also some small airports which have a rail connection (for instance, Dresden, Leipzig-Halle) or where the rail connection is under preparation. When making a decision about an appropriate transport mode, passengers are paying attention more and more to the time spent in transport. This time comprises of several parts which may be split into the main transportation phase (time when the passenger physically moves from one place to another) and secondary transportation phase (period when the passenger does not move anywhere). While in the past the greatest attention was given to the main phase (effort to maximize the speed of transport means etc.), at present there is a trend of an allembracing focus on the total period of transportation, thereby also including the secondary phase. The so called concept of minimum connecting time is followed. 


\section{For the integration of high speed tracks (HST) and air transport, there are two ways of mutual interconnection existing:}

- HST goes through a railway station located directly in the area of the airport, within walking distance for airport passengers, eventually accessible by internal airport transport,

- the airport is connected to such a network through a suburban rail line, and eventually through a specialized speed rail (e.g. Heathrow Express in London, etc.).

\section{Service level compatibility must focus on the following aspects:}

- an equal offer of intermodal transport services in the sales distribution network, including code sharing (hitherto the privilege of air transport only), check-in down to the final destination, irrespective of the fact whether the transport starts with air mode and ends HST, or vice versa

- global computerized distribution systems should include both air transport and railway segments with no discrimination, i.e., one transport mode cannot be preferred above any other one. These systems must be able to issue both types of travel documents, and must provide for their possible integration

- service staff (ground personnel of the air transport and railway personnel) must master issuance and acceptance of air, as well as railway transportation, documents and their administrative processing (booking and changes in booking, pricing, billing)

- time schedules or shuttle operation of HST connection to the airport must be mutually adjusted.

It seems that Frankfurt airport has made the greatest progress in the creation of an intermodal concept in Europe. Frankfurt airport is considered to be an intermodal transport hub, as the airport passengers have direct access to the long-distance trains of Deutsche Bahn's (German Rail) ICE-train network through the airport railway station. According to the opinion of Fraport AG company, with the further expansion of the European high-speed rail network FRA will be one of the most significant integrated transportation centres on the Continent. The inter-modal system of Frankfurt airport is designated as AIRail Service. Operating successfully on the Frankfurt - Stuttgart (since May 2001) and Frankfurt Cologne (since May 2003) routes, the cooperative AIRail Service ("train to the plane") by Deutsche Lufthansa AG, Deutsche Bahn AG, and Fraport AG, also started serving the Frankfurt - Siegburg/Bonn route at the beginning of November 2007. According to the "seamless travel" principle, travellers pass the check-in at the central train stations to receive the boarding passes for their onward flight from Frankfurt Airport. (At the Stuttgart and Cologne stations, the check-in counters are at the train station; at Siegburg/Bonn, an automatic check-in machine is located at the DB Travel Centre). Upon arrival at FRA's long-distance train station AIRail passengers have to check in their baggage at the LH baggage drop counter in the AIRail Terminal. The AIRail Terminal is located directly adjacent to FRA's long-distance train station. Having baggage check-in and baggage claim directly at the AIRail Terminal significantly contributes to the convenience of passengers making their way through the terminals to and from the aircraft.

The Swiss model allows for the check-in of airport passengers, including their baggage, usually a maximum of 24 hours before departure in more than fifty Swiss railway stations. At the same time, the passenger receives the Boarding Card containing information with the seat which has been allocated to the passenger. Such services allow the passenger to be mobile without baggage a day before departure and to avoid possible waiting for checkin at the airport. The passenger has to present necessary documents for the check-in: airplane ticket for each passenger with $\mathrm{OK}$ reservation, possibly an electronic airplane ticket, 
and passport if a visa is required. This service is provided for flights from Zurich and Geneva operated by 25 companies, and, in fact, for all charter flights from Zurich and Geneva, except for flights to the USA. Detailed information about check-in and transportation of baggage in the system air-rail, as well as precise time schedules for check-in and baggage claim, may be obtained at www.rail.ch/check-in website.

A similar service is also provided to arriving passengers. The baggage of passengers arriving to Switzerland from airports all over the world is delivered directly to the final railway station in Switzerland through the airports of Zurich and Geneva, irrespective of the company the passenger flew with. When arriving at the airport, the baggage is transported in an automated way right down to the final destination railway station. Swiss transfer tickets (sold only abroad) also include the way from the airport or from the boarder to the point of the final destination.

A similar air inter-modal terminal has been built up in CDG airport in Paris and in some other European airports, as well as on other continents.

\section{RISK ANALYSIS OF THE PRAGUE AIRPORT PROJECT}

\subsection{PRAGUE RUZYNE AIRPORT}

Prague Ruzyne airport is located in the centre of Europe. In relation to this location it applies for the function of hub with the function of a transfer junction. In the year when the main runway RWY 06/24 was commissioned (1963), one million passengers travelled through the Prague airport. In 2007 this had risen to 12.5 million of them. Although the number of passengers has increased more than twelve times since 1963, the system of runways has remained nearly without any change since that time. As the interest of travellers in Prague and the Czech Republic does not show any signs of ceasing, the airport expects a further growth in number of passengers and airplanes serviced in the future. In 2012 fifteen million passengers are expected to pass the airport gates, and in 2019 the airport plans to exceed the level of twenty million passengers.

Table 1: Number of passengers growth forecast for Prague Ruzyne airport

\begin{tabular}{|l|c|c|c|c|c|c|c|c|c|c|c|c|c|c|c|c|c|}
\hline \multicolumn{1}{|c|}{ Traffic } & & 2006 & $\mathbf{2 0 0 7}$ & $\mathbf{2 0 0 8}$ & $\mathbf{2 0 0 9}$ & $\mathbf{2 0 1 0}$ & $\mathbf{2 0 1 1}$ & $\mathbf{2 0 1 2}$ & $\mathbf{2 0 1 3}$ & $\mathbf{2 0 1 4}$ & $\mathbf{2 0 1 5}$ & $\mathbf{2 0 1 6}$ & $\mathbf{2 0 1 7}$ & $\mathbf{2 0 1 8}$ & $\mathbf{2 0 1 9}$ & $\mathbf{2 0 2 0}$ \\
\hline PAX & Mil & 11,5 & 12,1 & 12,7 & 13,3 & 14 & 14,7 & 15,4 & 16,1 & 16,9 & 17,6 & 18,3 & 19 & 19,8 & 20,5 & 21,2 \\
\hline MVT & Tis & 166 & 170 & 187 & 191 & 198 & 205 & 213 & 220 & 227 & 236 & 244 & 252 & 259 & 266 & 274 \\
\hline Transfer PAX & $\%$ & 19,8 & 20,7 & 21,7 & 22,7 & 23,7 & 24,7 & 25,7 & 26,7 & 27,7 & 28,2 & 28,7 & 29,2 & 29,7 & 30,2 & 30,7 \\
\hline & & & & & & & & & & & & & & & & \\
\hline
\end{tabular}

At the beginning of 2006, a new Terminal 2 was opened which increased the capacity of service for another 10 years in one shot. On the other hand, the system of runways is not sufficient any more in the period of operational peaks, and without expansion it would become the main obstacle in the planned development of the Ruzyne airport. Prague airport plans opening and putting into operation a new parallel RWY in 2013-2015. Uncertainty with the term is caused by complications in the implementation of this project. The government of the Czech Republic approved the document "Czech Republic's Territorial Development Policy 2008" in July 2009 which also includes the parallel runway of Prague Ruzyne airport.

The company Letiště Praha (Prague Airport) was established in the frame of privatisation transformation from the state company Správa letiště Praha, s.p. (Prague Airport Administration, state enterprise) in February 2008. As of December $1^{\text {st }}, 2008$ the company Letiště Praha, a.s. took over all rights and obligations of the previous state company, 
as well as its employees, business permissions, certifications, licences, and all processes and resources necessary for the functioning of the airport.

\subsection{ORGANIZATIONAL ARRANGEMENT OF THE PROJECT TO BUILD A RAILWAY CONNECTION BETWEEN PRAGUE AIRPORT AND KLADNO}

Cities and other entities interested in the construction of a modern railway connection between Prague - Prague Ruzyne airport - Kladno established the joint-stock company PRaK in 1993, the activity of which focuses on the implementation of the abovementioned project. Kladno is the largest town in the Central Bohemian region (about 75 thousand inhabitants) with a strong relation to Prague airport and Prague capital city, and also represents an important background base for universities. The whole project has been divided into two stages, namely the $1^{\text {st }}$ stage (Prague, Prague Ruzyne airport) and the $2^{\text {nd }}$ stage (railway station Prague Ruzyne - Kladno). Upon the grounds of documentation processed, especially in respect of traffic and construction solutions, there was a feasibility study of railway connection Prague - Ruzyne airport - Kladno processes in the frame of PHARE 9303-01-24 project in 1996. It was produced by the English engineering company Mott McDonald Limited in co-operation with Czech engineering companies. The study confirmed the uniqueness of the technical solution and provided direct, as well as indirect, economic, transport, and ecological merits of the project. Another advantage was that the study also determined the costs demands related to the project and defined the need for state subsidies, namely for reconstruction, doubling of rails and the electrification of the existing Prague-Kladno rail. Another important finding arising from the study was the clear argument that if the tariff principles of municipal and suburban traffic, as applied in Prague and the Central Bohemian region, were met it would be impossible, if no acceptable solution for investment incentive were provided by the state, to expect a direct payback of investment which could create an interest in the private sector to be involved in the project,. After the establishment of the new regional arrangement of the Czech Republic in 2000, the newly created Central Bohemian region started providing support to the abovementioned project, considering the section Prague - Kladno to be a pilot project for the Regional metropolitan rail system of public transport. This system is a part of the adopted Program of Regional Development as a part of the future system of traffic service in the region.

After many years of professional, as well as public, discussions, and many reports and studies processed in respect of the connection between the Prague airport and the centre of the city using underground or railway, the present situation may be characterized as follows:

- Both transport systems do not exclude each other in the Prague agglomeration, but complement each other due to the fact that the rail system shall also perform the role of a municipal railway in Prague.

- For the integration of air and rail transport, it is necessary to create a direct connection between the Prague Ruzyne airport and main railway station in Prague, where the longdistance trains stop (including the future high-speed lines). Discussions and preparatory work has already started in respect of a connection between "Masarykovo railway station" and the main railway stations in Prague.

The modernization of the railway Prague - Kladno with the branch line to Prague Ruzyne airport is embodied in the "Memorandum on Co-operation in Railway Traffic in the Area of Prague and the Central Bohemian region between the Ministry of Transport of the CR, Railway Infrastructure Administration (SZDC), Czech Railways, Capital City of Prague 
and the Central Bohemian Region" dated on July 2004. The Ministry of Transport and the Government of the CR consider the $1^{\text {st }}$ stage of the project - the connection between Prague Ruzyne airport and the centre of Prague - as the most appropriate railway project for the implementation of the investment strategy known as "PPP" - public private partnership. The government resolution, dated January $19^{\text {th }}, 2005$, included the project "Modernization, operation and maintenance of the railway Prague, "Masarykovo railway station - railway station Prague Ruzyne and the construction of a new branch line, including its operation and maintenance, between Prague Ruzyne station and Ruzyne airport" in the first row of PPP projects under the code AirCon. Under the Act on the Transformation of Czech Railways, state organization (Act no. 77/2002 Sb.), Czech Railways ceased to exist on December $31^{\text {st }}, 2002$. By January $1^{\text {st }}, 2003$ two new successor companies were formed, namely Czech Railways and Czech Railways Cargo, joint-stock company and state enterprise Railway Infrastructure Administration (SZDC). This is why SZDC has become the investor of the project concerned (for the modernization of existing rails and construction of the new branch to Prague airport).

\section{RISK ANALYSIS OF THE PRAGUE AIRPORT - RAILWAY NETWORK CONNECTION PROJECT}

When looking for a solution to the project, all possibilities for the utilisation and modernization of existing rail tracks leading from Prague to the airport area and to Kladno town were considered. For the purpose of a clear comparison of all possible alternatives, the Ministry of Transport of the CR gave an order to the Czech Technical University in Prague, Faculty of Transportation Sciences to produce a comparative study of all the alternatives, including risk analysis, in 2007. The following Figure 1 shows the routes of all alternatives, which all require modernization and eventually construction of new missing tracks.

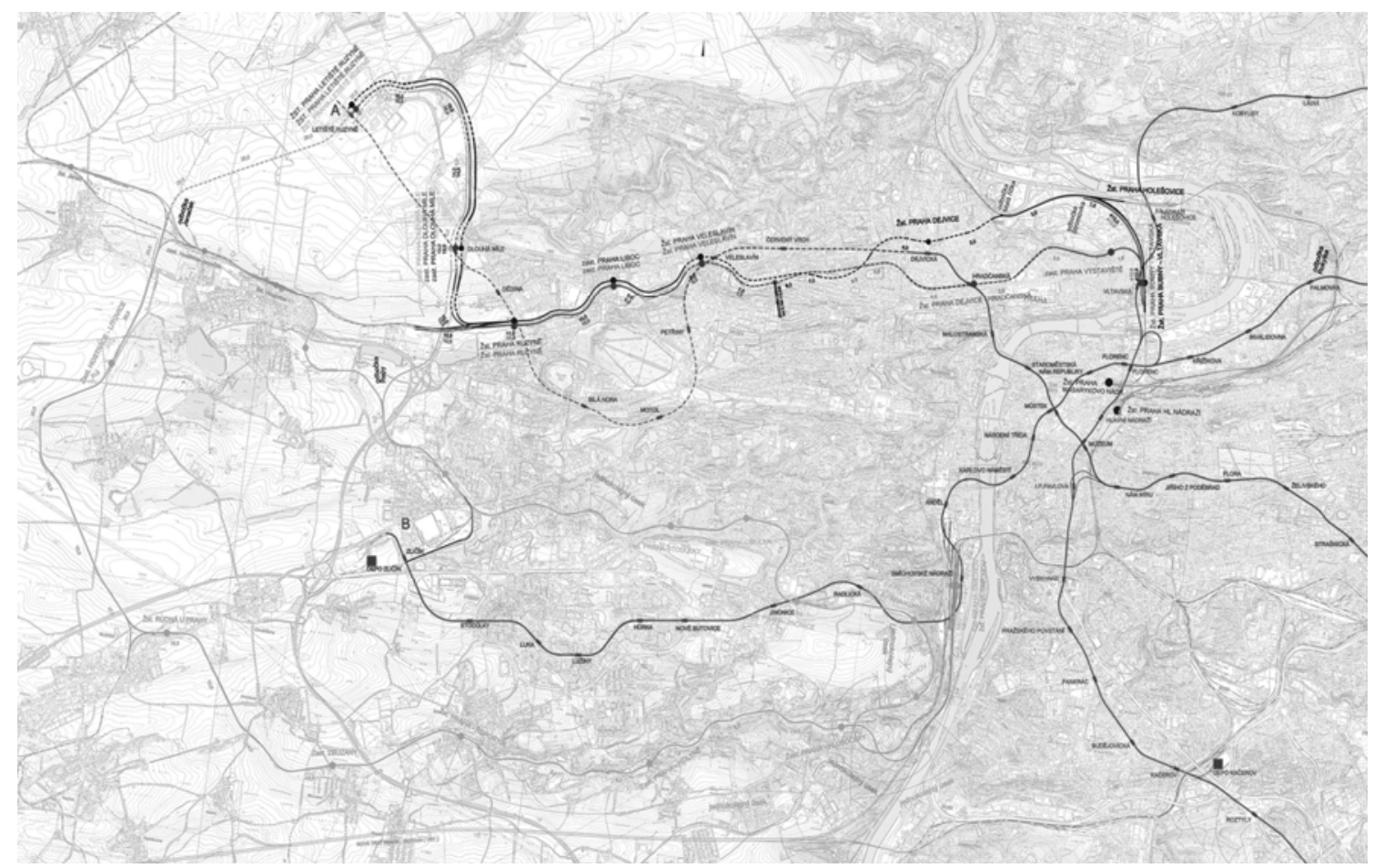

Figure 1: Map showing assessed alternatives for the connection between Prague city and Prague airport (Metroprojekt Praha, a.s.) 
The subject matter of the risk analysis consisted of the options of the project for the railway link Prague - Prague Ruzyne Airport - Kladno, named according to the established names and designations of the railway tracks:

- Option „Rudenska“ - R (green)

- Leading in the existing corridor of track no. 173 (Prague Main Station) - Prague Smichov station - Rudna u Prahy and track no. 122 Rudna u Prahy - Hostivice, with a new construction of the branch Jenecek - Ruzyne airport;

- Option „Semmering“ - S (violet)

- Leading mainly in the existing corridor of track no. 122 (Prague Main Station) Prague Smichov - Prague Zlicin - Hostivice - (Kladno), with a new construction in the area of Prague Zlicin (eventually branch Repy - Ruzyne airport);

- Option „Bustehradska“ - B (red)

- Leading mainly in the existing corridor of track no. 120 Prague Masarykovo railway station - Prague Bubny - Hostivice - Kladno, with a new construction of the branch Prague Ruzyne - Ruzyne airport;

- Option „Holesovice“ - H (blue)

- Leading in the track (Prague Main Station) - Prague Holesovice - branch Mala Ricka in the corridor of track no. 091, a new construction down to station Prague Veleslavin, and then following the option „Bustehradska“, i.e., track Prague Veleslavin - Prague Ruzyne in the corridor of the existing track no. 120, with a new construction of the branch Prague Ruzyne - Ruzyne airport.

The purpose of analysing the risks associated with these alternatives was to minimise the risk of failure of the alternatives - to identify the least risky version of the railway connection. The risk was understood as an event (generally called a risk factor), which can negatively influence the expected results of the examined alternatives of the connection.

\section{The risk analysis was supposed to clarify:}

- which risk factors are significant and most strongly influence the risk of the given alternative (or possibly which factors are insignificant and can be disregarded);

- how high the risk of the given alternative is and whether this risk is still acceptable or whether it is already beyond the limit of acceptability (risk assessment);

- what measures can be taken to reduce the risk of the given alternative down to an acceptable level (risk management).

Therefore, the analysis of the risks associated with the alternatives of the railway link was divided into the following stages:

- identifying the risk factors of the alternatives

- identifying the significance of the risk factors of individual alternatives

- identifying the risks of individual alternatives

\subsection{IDENTIFYING THE RISK FACTORS OF THE ALTERNATIVES OF THE RAILWAY LINK}

The basis for identifying risk factors consisted of the knowledge, experience and intuition of the employees who had participated in the preparation and implementation of the projects 
of a similar nature in the past. The actual identification of risk factors made it easier to structure the qualities of risk events (their contents) from the following points of view:

1. The point of view of the infrastructure investor.

2. The point of view of the local administration as the regulator responsible for the development of the territory and the owners of complementary enterprises.

3. The point of view of the infrastructure users (citizens).

Such an approach allows for a dialogue among all the involved entities; it is possible to analyse the differences in risk perception. The result of this stage is a written record of all the identified risk factors which can endanger the railway link project and which are structured according to the above-mentioned three points of view of the risk events' qualities [6]:

\section{Risks on the part of an investor:}

1. Risk on the part of a project leader

2. Risk on the part of construction

3. Risk of exceeding the investment costs

4. Risk of failure in the implementation of the project funding model

5. Risk of failure in keeping the project time schedule

6. Risk of failure in keeping project parameters

7. Risk of technical and engineering complications

8. Risk of permit procedures

9. Risk of appellate procedures

10. Environmental risks

11. Risks related to preservation of historical monuments

12. Risk of reduced revenues

\section{Risks on the part of the local administration:}

13. Risk of induced investments to city public traffic (MHD)

14. Risk of induced operational costs of MHD

15. Risk of increased expenditures related to the acquisition of real estates and land from private owners

16. Risk of not finishing the implementation of the territorial development plan

17. Risk of a wrong political decision

18. Risk of lack of co-ordination

19. Risk of other than expected impacts of the project

\section{Risks on the part of infrastructure users (public):}

20. Risk of longer travel time

21. Risk of increased vulnerability of the infrastructure

22. Risk of accident rate and transportation of dangerous materials

A high number of the identified risk factors could make further stages of risk analysis considerably more difficult. Yet, some of these factors can be entirely insignificant. This was why, subsequently, the significance of the risk factors was examined by experts, 
which made it possible to reduce the number of risk factors, which were then taken into account.

\subsection{IDENTIFYING THE SIGNIFICANCE OF RISK FACTORS AND IDENTIFYING THE RISK OF THE EXAMINED ALTERNATIVES}

The essence of the evaluation of the significance of risk factors by experts consist in this significance being examined by a group of experts from two points of view. The first point of view concerns the probability of occurrence of the risk factor. Thus, the threat that an undesired event will occur will be expressed as the probability of its occurrence $(\mathbf{O})$. For quantification of the probability of occurrence of an event, the following scale was chosen [6]:

\section{Degree The occurrence of the event is}

1 Improbable

2 Slightly probable

3 Averagely probable

4 Considerably probable

$5 \quad$ Almost certain

The second point of view is based on the intensity of the negative effect, the impact that the occurrence of the risk factor has on the success of the project alternative being examined. The impact (I) caused by an undesired event is expressed by its scope (extent) in which it affects the protected interests of the involved party. The following scale was chosen:

\section{Degree The impact of the event is}

$1 \quad$ Negligible

$2 \quad$ Small

$4 \quad$ Medium

$8 \quad$ Large

16 Critical

With regard to the endangerment of the project's success, a risk factor (an undesired event) is the more significant, the more probable its occurrence is and the higher the intensity of the negative impact of this factor is. The risk factors that need to be regarded as significant are not only those risk factors whose probability of occurrence and, simultaneously, whose intensity of negative impact are high, but are also those risk factors whose probability of occurrence is very low but the intensity of their negative impacts is high. Therefore, for quantitatively assessing the significance of risk factors, it is not possible to choose the same linear scales for assessing both the probability and the intensity of a negative impact. If we used the scale of $1,2,3,4$ and 5 for the probability-related assessment, then it is necessary to use a non-linear scale, such as $1,2,4,8$ and 16, for assessing the intensity of a negative impact. 
Fig. 2 shows the tabular representation of the significance of risk factors, seen from these two points of view. Both the probability of occurrence of the risk factors and the intensity of their negative impacts has five degrees in the above-mentioned chosen scales:

Based on an expert examination of the significance of risk factors, it is possible to arrive at a numerical rating of these significance levels, which is known as scoring. According to the results of the risk analysis (the probabilities and impacts of undesired events), risk assessment is carried out according to the chosen criterion values referred to as the "score" $(\mathbf{O} \times \mathbf{~ I})$, which determines the gravity and acceptability of the risk. The variability of the score is also shown in the figure, based on the chosen scales. In the scoring process, the importance of the choice of a non-linear scale for rating the intensity of the negative impacts of the risk factors becomes even clearer. If a linear scale were used for the impact, such as 1, 2, 3, 4 and 5, then a factor with an almost certain occurrence and insignificant intensity of impact ( $5 \times 1=5$, that is, an insignificant factor) would be rated equally as a factor with a low probability of occurrence but with a critical intensity of its impact ( $1 \times 5=5$, which needs to be regarded as significant). If a risk is unacceptable, it is necessary to recommend carrying out a deeper risk analysis to identify the risks and subsequently to take measures to reduce the risks.

\begin{tabular}{|c|c|c|c|c|c|}
\hline \multicolumn{6}{|c|}{ Risk assessed } \\
\hline $\begin{array}{c}\text { Negative effect } \\
\text { assessment }\end{array}$ & \multicolumn{5}{|c|}{ Probability assessment } \\
\cline { 2 - 6 } & 1 & 2 & 3 & 4 & 5 \\
\hline 16 & 16 & 32 & 48 & 64 & 80 \\
\cline { 2 - 6 } & 8 & 16 & 24 & 32 & 40 \\
\cline { 2 - 6 } 4 & 4 & 8 & 12 & 16 & 20 \\
\cline { 2 - 6 } 2 & 2 & 4 & 6 & 8 & 10 \\
\cline { 2 - 6 } 1 & 1 & 2 & 3 & 4 & 5 \\
\hline
\end{tabular}

Figure 2: Tabular representation of the significance of risk factors

The values of the $\mathbf{O} \mathbf{x} \mathbf{I}$ criterion for identifying risk acceptability have been chosen as follows:

$$
\begin{gathered}
\text { O x I } \\
1-8 \\
10-24 \\
32-80
\end{gathered}
$$

\author{
Risk rating \\ the risk is acceptable \\ the risk is conditionally acceptable \\ the risk is unacceptable
}

The individual risks for each assessed alternative of the project, that is, $\mathbf{S}, \mathbf{R}, \mathbf{B}$ and $\mathbf{H}$, can be sorted in this way according to their respective scores and it is thus possible to identify clearly the priorities with respect to further management of the project risks.In [6], we can find the identified tabular representations of the significance level of each risk factor.

It also contains a summarised overview of the results of the risk analysis in a graphical presentation in the form of bar charts for the purposes of further analyses and recommendations: the results of the risk analysis are shown for each of the alternatives $\mathbf{S}$, 
$\mathbf{B}, \mathbf{R}$ and $\mathbf{H}$, where the individual risks are arranged in the order from the highest one to the lowest one, and the results of the comparison of the risks associated with the alternatives from the points of view of the investors, the local administration, and the transported public are shown. From the point of view of the three main parties involved, for example, three conclusions were drawn:

- On the part of railway infrastructure investor: classical three risks related to any largescope project are dominating:

- Maintaining the budget - Risk of exceeding the investment costs, of failure in the implementation of the project funding model,

- Keeping the time schedule - Risk of permit procedures, Risk of appellate procedures

- Maintaining the quality of the project - Risk of technical and engineering complications.

Last but not least Environmental risk and risk of reduced revenues turned to be important, too. The mentioned risks are effecting options $\mathbf{H}, \mathbf{S}$ and $\mathbf{R}$ most negatively.

- On the part of the local administration Risk of increased expenditures related to the acquisition of real estates and land from private owners, Risk of not finishing the implementation of the territorial development plan, Risk of lack of co-ordination, and Risk of other than expected impacts of the project are dominating. These risks are again effecting options $\mathbf{H}, \mathbf{S}$ and $\mathbf{R}$ most negatively. Also the Risk of induced investment costs is important and effects mostly option $\mathbf{B}$, too.

- On the part of public Risk of longer travel time dominates in options $\mathbf{R}$ and $\mathbf{S}$. Risk of increased vulnerability and Risk of increased accident rate dominates in options $\mathrm{R}, \mathrm{S}$ and $\mathrm{H}$.

The scoring results shown in Fig. 2 can also be represented graphically in a bar chart:

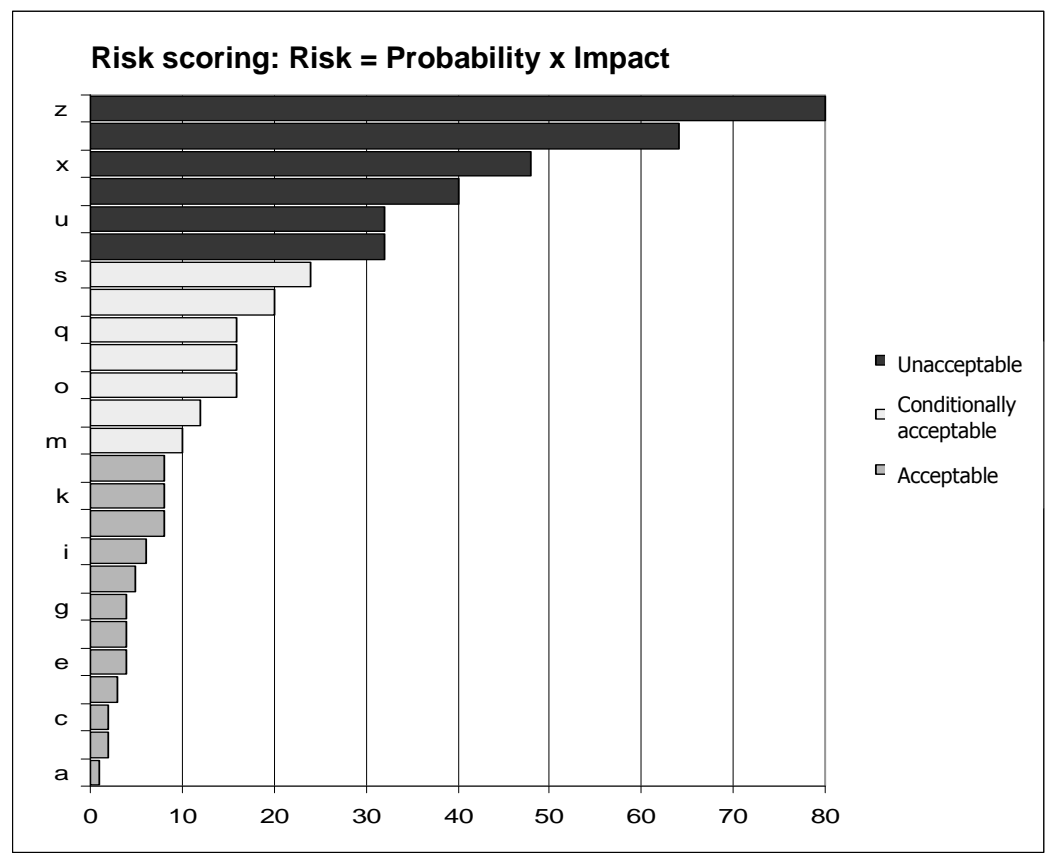


As the result of risk analysis there is a clear conclusion preferring the alternative „BUSTEHRADSKA“ - B. This option satisfies the principle requirements of the task (estimated period of implementation, proposed capacity, etc.) and goes through a sunk tunnel of $6.2 \mathrm{~km}$ in length to the built-up zone of Prague 6 borough which would eliminate the effect of certain risks as perceived by the local administration. This option was then accepted by the municipalities concerned, as well as by the Ministry of Transport.

The connection of Prague Ruzyne airport to the future network of high-speed railway tracks (HST) belongs to a different category. Together with the proposal of a new railway tunnel connection meeting the parameters of HST between Prague and Beroun town, and continuing further to Pilsner town and Germany, the possibility to bring the high-speed tracks to the Prague airport is being solved. This could be realized through a branch starting at the level of Barrandov branch. The branch would then turn North-West and would lead in parallel to the arrival and departure runway RWY 13/31. The precise location of the station has not yet been determined. The track would then continue to the North and would be connected to HST leading to Dresden.

\section{CONCLUSIONS}

This article describes some principles and findings related to the harmonization of air and rail transport. Together with ground road connection, the hubs turn to inter-modal terminals for the transportation of passengers and goods. Such a defined inter-modal system shall probably be the solution for the present time, as well as for the future and may integrate the benefits of air and high-speed rail transport. The presentation also describes the history of long-term preparation of the railway connection to Prague Ruzyne airport and its assurance, including a risk analysis of such connection alternatives. Risk identification, assessment and management is a process, the goal of which is to optimise the risk. The first part of the process, which involves identifying, assessing and comparing the risks, provides the source materials necessary for the second part of the process, in which measures are taken to reduce the risks down to an acceptable level (effort to achieve an acceptable risk). While the first part of the process - risk identification and assessment - can be regarded as a purely scientific (multidisciplinary) activity, risk management also includes a political aspect, in addition to scientific disciplines (economics, sociology, psychology), due to the possible impacts of the taken measures.

The Prague project has been targeted as one of the pilot PPP financial strategy projects.

\section{REFERENCES}

BÍNA, L.: The Integration of Air and Rail Transports: Current Situation and future Perspective. In: Scientific Papers of the University of Pardubice. Series B. The Jan Perner Transport Faculty 9 (2003).

MOJŽÍŠ, V., MOLKOVÁ, T., BÍNA, L.: Perspektiven des Eisenbahn- und intermodalen Verkehrs in zusammenwachsenden Europe. In: ZEVrail, Mai 2004, 5, s.182-186, ISSN 1618-8330.

BÍNA, L.: The Integration of Air and Railway Transport and Information Systems, Proceedings PISTA'04, Orlando, USA, 2004. 
BÍNA, L.: Integration des Flug-und Eisenbahnverkehrs und ihre Realisierung in der Tschechischen Republik. In: ZEVrail, März 2005, 3, s.75-81, ISSN 1618-8330.

PALAN, M.: Connectivity of Air and Rail Transport and its Application in the Czech Republic and in Europe, doctoral dissertation, University of Pardubice Jan Perner Transport Faculty, 2007.

MOOS, P., BÍNA, L., KUBÁT, B., PASTOR, O., SKUROVEC, V.: Posouzení variant železničního spojení Praha - Letiště Praha Ruzyne - Kladno (Evaluation of the Variants of the Railway Connection Prague - Prague Airport), Project for the Ministry of Transport of the Czech Republic, 2007. 